\title{
Peculiarities of Professional Training of Specialists of Helping Professions
}

\author{
Sapargaliyeva Aizhan Zhanysovna ${ }^{1}$, Aralbayeva Ryszhamal Kadyrovna ${ }^{1}$ \& Rysbekov Kadyr Koishybekovich ${ }^{1}$ \\ ${ }^{1}$ Zhetysu State University named after I. Zhansugurov, Kazakhstan \\ Correspondence: Sapargaliyeva Aizhan Zhanysovna, Zhetysu State University named after I. Zhansugurov, \\ Kazakhstan. E-mail: aizhan_sapargaliyeva@mail.ru
}

Received: December 13, 2014 Accepted: January 15, 2015 Online Published: April 30, 2015

doi:10.5539/ass.v11n12p229 URL: http://dx.doi.org/10.5539/ass.v11n12p229

\begin{abstract}
The article reveals the peculiarities of training of specialists of helping professions. Conducted a formative experiment, which reflects the received data. Developed pedagogical conditions of formation of professional competence of specialists of helping professions: special, communicative and personal. Selected pedagogical conditions promoting the formation of professional competence: the course, the ongoing practice during the entire period of study at the University with clarification and elaboration of goals, objectives and content of training as an innovative method of extracurricular work with students of 1st-4th courses with a professional orientation.
\end{abstract}

Keywords: professional activity, specialists of helping professions, competence, special, communicative, personal, pedagogical conditions, higher education, principles

\section{Introduction}

One of the priority tasks of higher education is the preparation of a new, flexible, competitive, competent, highly skilled professional with a broad fundamental knowledge, initiative, able to approach creatively the solution of professional problems, able to adapt quickly to the continuously changing requirements of the labour market, capable to perform professional activities effectively and be responsible for its results (Sapargaliyeva, Aralbaeva, Sheryazdanova, \& Rysbekov, 2013).

\section{The Main Part}

The professionalization of helping professionals associated with the formation of the functional specificity of the profession, i.e. the set of functions on the basis of which it is possible to identify a professional position or the professional role of the social pedagogue - psychologist and psychologist. The development of professional training of specialists helping professions in modern conditions is influenced by a number of contradictions that characterize the process of formation of the functional specificity of the profession of social pedagogue psychologist and psychologist (Markova, 1996).

On the bases of analysis of the sources we found that professional competence is fundamental to the effectiveness and success of professional activity of a specialist, in particular, of specialists of helping professions (Platonova \& Platonov, 2011; Sheryazdanova \& Aralbaeva, 2012). According to the research of A. K. Markova, we give the definition of the essence of the concept "professional competence" of specialists of helping professions (Markova, 1996).

In our understanding of the professional competence of specialists of helping professions is an integral, dynamic, rapidly evolving characteristic of the subject of professional activity, which consists of a special, personal competence and competence in communication; which is the basis for effective and successful professional career.

In the structure of each component of professional competence, we will identify four interrelated components: motivational, Gnostic, procedural and evaluative-reflexive. This composition is the basis for the definition of criteria, indicators of special, personal competences and competence in communication. 


\section{Results and Discussion}

In our work were identified pedagogical conditions of formation of professional competence of the specialists of helping professions which is included into the organizational-technological unit of the developed model.

As the complex of pedagogical conditions we understand the rational combination of specially created circumstances conducive to the formation of professional competence. The formation of professional competence of specialists of helping professions can be achieved if these conditions are interrelated and mutually complement.

We proposed the following conditions:

- Introduction of the course "Formation of professional competence of specialists of helping professions";

- To conduct continuous practice during the entire period of study at the University with clarification and elaboration of goals, objectives and content;

- To use training professional competence of professionals;

- Conducting of extracurricular work on psychology and pedagogy, with a professional focus.

The complex of identified pedagogical conditions is the psycho-pedagogical support of students -specialists of helping professions during the entire period of study at the University, based on the principles of learner-centered education with the use of innovative technologies, i.e. the organization of educational process on the basis of innovative methods and forms of education.

\section{Experiment Methodology}

A formative experiment was planned with the aim of experimental verification of the effectiveness of selected pedagogical conditions of formation of professional competence of specialists of helping professions in the educational process of the University. In the process of forming experiment was conducted intermediate test, and the final stage of experimental work on the formation of professional competence of specialists of helping professions in the higher school was the control experiment (control test).

As we have selected two experimental groups 1 and 2 courses (2012-2014 academic year), the implementation of pedagogical conditions were slightly different. Let us denote groups of examinees: the first and second experimental groups $1-4$ courses (60 people).

So, for example, in the first course (the first experimental group, 2011-2012 academic year) were implemented the following pedagogical conditions: in the first course (2011-2012 year) - the practice "Introduction into the professional activities" (2nd semester); in the second course (2012-2013 year) were introduced: the course "Formation of professional competence of future specialists of helping professions" (3rd semester), the practice "Methodology of scientific research" (4 semester); in the third course (2013-2014 year) was conducted: "The training of professional competence of specialists of helping professions" (5 semester), psycho-social pedagogical practice and extracurricular work on pedagogy and psychology (6th semester).

Following the second experimental group - 2nd year students (2012-2013 year) was also tested by a formative experiment. Starting from the second course (2012-2013 year), with this group of examinees were conducted the following activities: course "Formation of professional competence of future specialists of helping professions" (3rd semester), the practice "Methodology of scientific research" (4 semester); in the third course (2013-2014 year) were introduced: "the Training of professional competence of specialists of helping professions" (5 semester), psycho-social pedagogical practice (6th semester); in the fourth course (2014-2015 year) was conducted practical training at the pedagogical College (7 semester), extracurricular work in pedagogy and psychology, pre-diploma practice (7th semester).

Intermediate test of the students of first experimental group was held at the end of the second course in the 4th semester (2012-2013 year). In this period was provided the introduction of the higher education component of the curriculum the following pedagogical conditions: the practice "Introduction into the professional activity" (2 semester), course "Formation of professional competence of specialists of helping professions (3rd semester), practice "Methodology of scientific research" (4th semester).

The intermediate test of students of the second experimental group was held at the end of the third course in the 6th semester (2013-2014 year). During this period we have implemented the following pedagogical conditions: the course "Formation of professional competence of future specialists of helping professions" (3rd semester), the practice "Methodology of scientific research" (4th semester), "Training of professional competence of specialists helping professions" (5 semester), psycho-social pedagogical practice (6th semester).

The results of the experimental data presented in Tables 1,2 . 
Table 1. Level of formation of the components of each component of professional competence of students of 2 nd year 2012-2013 (the first group)

\begin{tabular}{|c|c|c|c|c|c|c|c|c|c|}
\hline \multirow{3}{*}{$\begin{array}{l}\text { Components of professional } \\
\text { competence }\end{array}$} & \multirow{3}{*}{ components } & \multicolumn{8}{|c|}{ Level, $\%$} \\
\hline & & \multicolumn{2}{|c|}{ High } & \multicolumn{2}{|c|}{ sufficient } & \multicolumn{2}{|c|}{ average } & \multicolumn{2}{|c|}{ Low } \\
\hline & & $\mathrm{CG}$ & EG & $\mathrm{CG}$ & EG & $\mathrm{CG}$ & EG & $\mathrm{CG}$ & EG \\
\hline \multirow{4}{*}{ Special competence } & Motivational & & & 26,1 & 36,4 & 43,5 & 45,4 & 30,4 & 18,2 \\
\hline & Gnostic & & & & & 21,7 & 40,9 & 78,3 & 59,1 \\
\hline & Procedural & & & & & 17,4 & 36,4 & 82,6 & 63,6 \\
\hline & Estimative-reflective & & & & & 13,0 & 31,8 & 87,0 & 68,2 \\
\hline \multirow{4}{*}{ Communicative competence } & Motivational & & & 30,4 & 40,9 & 43,5 & 45,5 & 26,1 & 13,6 \\
\hline & Gnostic & & & & & 26,1 & 45,5 & 73,9 & 54,5 \\
\hline & Procedural & & & & & 21,7 & 40,9 & 78,3 & 59,1 \\
\hline & Estimative -reflective & & & & & 17,4 & 31,8 & 82,6 & 68,2 \\
\hline \multirow{4}{*}{ Personal competence } & Motivational & & & 30,4 & 40,9 & 43,5 & 40,9 & 26,1 & 18,2 \\
\hline & Gnostic & & & & & 21,7 & 40,9 & 78,3 & 59,1 \\
\hline & Procedural & & & & & 21,7 & 36,4 & 78,3 & 63,6 \\
\hline & Estimative-reflective & & & & & 17,4 & 36,4 & 82,6 & 63,6 \\
\hline
\end{tabular}

Table 2. Level of formation of the components of each component of professional competence of students of 3rd course 2013-2014 (second group)

\begin{tabular}{|c|c|c|c|c|c|c|c|c|c|}
\hline \multirow{3}{*}{$\begin{array}{l}\text { Components of } \\
\text { professional } \\
\text { competence }\end{array}$} & \multirow{3}{*}{ Componennt } & \multicolumn{8}{|c|}{ Level, \% } \\
\hline & & \multicolumn{2}{|c|}{ high } & \multicolumn{2}{|c|}{ sufficient } & \multicolumn{2}{|c|}{ average } & \multicolumn{2}{|c|}{ Low } \\
\hline & & CG & EG & CG & EG & KG & EG & KG & EG \\
\hline \multirow{4}{*}{$\begin{array}{c}\text { Special } \\
\text { competence }\end{array}$} & Motivational & & & 31,8 & 47,8 & 40,9 & 43,5 & 27,3 & 8,7 \\
\hline & Gnostic & & & 13,6 & 26,1 & 50,0 & 60,9 & 36,4 & 13,0 \\
\hline & Procedural & & & 9,1 & 26,1 & 50,0 & 52,2 & 40,9 & 21,7 \\
\hline & Estimative-reflective & & & & 21,7 & 45,5 & 52,2 & 54,5 & 26,1 \\
\hline \multirow{4}{*}{$\begin{array}{l}\text { Communicative } \\
\text { competence }\end{array}$} & Motivational & & & 40,9 & 52,2 & 36,4 & 43,5 & 22,7 & 4,3 \\
\hline & Gnostic & & & 18,2 & 30,5 & 63,6 & 56,5 & 18,2 & 13,0 \\
\hline & Procedural & & & 13,6 & 26,1 & 50,0 & 56,5 & 36,4 & 17,4 \\
\hline & Estimative -reflective & & & & 26,1 & 45,5 & 39,1 & 54,5 & 34,8 \\
\hline \multirow{4}{*}{$\begin{array}{l}\text { Personal } \\
\text { competence }\end{array}$} & Motivational & & & 31,8 & 47,8 & 45,5 & 43,5 & 22,7 & 8,7 \\
\hline & Gnostic & & & 13,6 & 30,4 & 54,5 & 52,2 & 31,8 & 17,4 \\
\hline & Procedural & & & 13,6 & 26,1 & 50,0 & 56,5 & 36,4 & 17,4 \\
\hline & Estimative-reflective & & & & 21,8 & 50,0 & 47,8 & 50,0 & 30,4 \\
\hline
\end{tabular}

Thus, on the basis of the analysis of the tables we can conclude that after the implementation of the pedagogical conditions at this formative stage of the experiment the students of the experimental group have had positive changes: there has been sufficient growth and average levels and a reduction in low level. This suggests that pedagogical conditions implemented at this stage of a formative experiment, contribute to the improvement of professional competence.

To determine the level of development of each component of professional competence of helping professions students according to the results of a formative experiment was carried out a control experiment.

Control experiment the students first experimental group was conducted at the end of 3 course, 6 semester (2013-2014 academic year). In this period was provided for the implementation of the following pedagogical conditions: "the Training of professional competence of students helping professions" (5 semester), psycho-social pedagogical practice and extracurricular work in pedagogy and psychology (6th semester).

According to the results of practices in the pedagogical College ( 7 semester), Department of pedagogy and psychology ( 8 semester) with students in the second experimental group by the end of 4th year, 7th semester (2014-2015 academic year) was conducted a control experiment.

In Tables 3 and 4 it is reflected a detailed picture of the levels of development of each component of professional competence of students helping professions after the introduction and implementation of pedagogical conditions. 
Table 3. Level of formation of the components of each component of professional competence of students of 3rd course 2013-2014 (control experiment, the first group)

\begin{tabular}{|c|c|c|c|c|c|c|c|c|c|}
\hline \multirow{3}{*}{ Component of prof. comp. } & \multirow{3}{*}{ component } & \multicolumn{8}{|c|}{ level \% } \\
\hline & & \multicolumn{2}{|c|}{ High } & \multicolumn{2}{|c|}{ sufficient } & \multicolumn{2}{|c|}{ average } & \multicolumn{2}{|c|}{ Low } \\
\hline & & $\mathrm{KG}$ & EG & $\mathrm{CG}$ & EG & $\mathrm{CG}$ & EG & $\mathrm{CG}$ & EG \\
\hline \multirow{4}{*}{ Special competence } & Motivational & & & 30,4 & 45,5 & 43,5 & 45,5 & 26,1 & 9,0 \\
\hline & Gnostic & & & 8,7 & 18,2 & 56,5 & 63,6 & 34,8 & 18,2 \\
\hline & Procedural & & & 8,7 & 18,2 & 47,8 & 59,1 & 43,5 & 22,7 \\
\hline & Estimative-reflective & & & & 18,2 & 43,5 & 50,0 & 56,5 & 31,8 \\
\hline \multirow{4}{*}{ Communicative competence } & Motivational & & & 34,8 & 50,0 & 43,5 & 45,5 & 21,7 & 4,5 \\
\hline & Gnostic & & & 13,0 & 22,8 & 60,9 & 63,6 & 26,1 & 13,6 \\
\hline & Procedural & & & 8,7 & 18,2 & 52,2 & 59,1 & 39,1 & 22,7 \\
\hline & Estimative - reflective & & & & 18,2 & 43,5 & 40,9 & 56,5 & 40,9 \\
\hline \multirow{4}{*}{ Personal competence } & Motivational & & & 30,4 & 45,5 & 43,5 & 45,5 & 26,1 & 9,0 \\
\hline & Gnostic & & & 8,7 & 22,7 & 60,9 & 54,6 & 30,4 & 22,7 \\
\hline & Procedural & & & 8,7 & 22,7 & 56,5 & 59,1 & 34,8 & 18,2 \\
\hline & Estimative-reflective & & & & 22,7 & 47,8 & 40,9 & 52,2 & 36,4 \\
\hline
\end{tabular}

Table 4. Level of formation of the components of each component of professional competence of students of the 4th year 2014-2015 (control experiment, a second group)

\begin{tabular}{|c|c|c|c|c|c|c|c|c|c|}
\hline \multirow{3}{*}{ Component of prof. comp. } & \multirow{3}{*}{ component } & \multicolumn{8}{|c|}{ level \% } \\
\hline & & \multicolumn{2}{|c|}{ High } & \multicolumn{2}{|c|}{ High } & \multicolumn{2}{|c|}{ high } & \multicolumn{2}{|c|}{ High } \\
\hline & & KG & KG & KG & $\mathrm{KG}$ & $\mathrm{KG}$ & $\mathrm{KG}$ & $\mathrm{KG}$ & $\mathrm{KG}$ \\
\hline \multirow{4}{*}{ Special competence } & Motivational & & 13,0 & 36,4 & 52,2 & 40,9 & 30,4 & 22,7 & 4,4 \\
\hline & Gnostic & & 8,7 & 18,2 & 34,8 & 59,1 & 47,8 & 22,7 & 8,7 \\
\hline & Procedural & & 8,7 & 18,2 & 34,8 & 54,5 & 43,5 & 27,3 & 13,0 \\
\hline & Estimative-reflective & & 8,7 & 9,1 & 21,7 & 50,0 & 52,2 & 40,9 & 17,4 \\
\hline \multirow{4}{*}{ Communicative competence } & Motivational & & 13,0 & 40,9 & 56,5 & 40,9 & 26,1 & 18,2 & 4,4 \\
\hline & Gnostic & & 13,0 & 22,7 & 34,8 & 59,1 & 43,5 & 18,2 & 8,7 \\
\hline & Procedural & & 13,0 & 18,2 & 30,4 & 59,1 & 43,5 & 22,7 & 13,1 \\
\hline & Estimative - reflective & & 8,7 & 9,1 & 21,7 & 50,0 & 47,8 & 40,9 & 21,8 \\
\hline \multirow{4}{*}{ Personal competence } & Motivational & & 17,4 & 40,9 & 52,2 & 40,9 & 26,1 & 18,2 & 4,3 \\
\hline & Gnostic & & 17,4 & 18,2 & 30,4 & 54,5 & 43,5 & 27,3 & 8,7 \\
\hline & Procedural & & 13,0 & 18,2 & 34,8 & 59,1 & 43,5 & 22,7 & 8,7 \\
\hline & Estimative-reflective & & 13,0 & 9,1 & 21,7 & 54,5 & 43,5 & 36,4 & 21,8 \\
\hline
\end{tabular}

After analyzing the data obtained, we can draw the following conclusions: in the second experimental group there was a significant increase of sufficient level and, most importantly, among some of students, we have revealed a high level of development of each component of professional competence. The increase occurred in all components of each component of professional competence. Significantly decreased the number of students with low and average level. The information given above allows us to conclude about the effectiveness of the implementation of the pedagogical conditions that contributed to the formation of professional competence of students of helping professions.

Thus, the data obtained on the results of formative and control experiment show positive dynamics of change in the level of formation of the components of each component of professional competence of students of helping professions, indicating the impact of the embedded pedagogical conditions of formation of professional competence in the preparation of the experimental groups

\section{Results of Experiment}

To validate the differences in outcomes in the control and experimental groups, we used Pirson's criterion $\chi^{2}$ (X-square) (Nasledov \& Tarasov, 2001).

The selected criterion allows to detect differences in the distribution characteristic when comparing two empirical distributions.

Calculation formula of criterion $\chi^{2}$ to compare two empirical distributions is the following: 


$$
\chi_{\text {эмn }}^{2}=\frac{1}{N \cdot M} \cdot \sum_{i=1}^{k} \frac{\left(N \cdot x_{i}-M \cdot y_{i}\right)^{2}}{x_{i}+y_{i}}
$$

where $\mathrm{N}$ and $\mathrm{M}$ are the number of elements in the first and in the second samples. These numbers can be the same or may be different, i.e. as an element of the sample can also be "zero";

$\mathrm{k}$ is the number of bits of evidence (levels highlighted in the study: "low", "average", "sufficient", "high");

$\mathrm{x}$ - empirical frequency obtained prior to conducting formative experiment;

$\mathrm{y}$ - empirical frequency obtained after conducting a formative experiment.

We will check the validity of the differences of the results of control and experimental groups on all components for each component of professional competence of students of helping professions. In our calculations we used the Excel program, which is part of the package of Microsoft Office programs (table 5).

In the first group consisted of students who had completed 1 to 3 of course, the second from 2 to 4 courses.

Table 5. Calculation of the $\chi^{2}$ by definition of the differences between experimental and control groups across all components of each component of professional competence

\begin{tabular}{cccccc}
\hline \multirow{3}{*}{ Component of prof. comp. } & & \multicolumn{4}{c}{$\chi_{\text {эми }}^{2}$} \\
\cline { 3 - 5 } & Component & \multicolumn{2}{c}{ First group } & \multicolumn{2}{c}{ Second group } \\
\cline { 3 - 5 } & & CG & EG & CG & EG \\
\hline \multirow{3}{*}{ Special competence } & Motivational & 5,4 & 27,9 & 3,1 & 31,0 \\
& Gnostic & 81,8 & 121,9 & 68,5 & 108,8 \\
& Procedural & 64,5 & 109,7 & 70,0 & 105,8 \\
& Estimative-reflective & 42,1 & 87,9 & 48,5 & 91,6 \\
& Motivational & 9,7 & 35,7 & 5,0 & 33,4 \\
Communicative competence & Gnostic & 94,8 & 135,3 & 71,2 & 94,0 \\
& Procedural & 69,6 & 106,0 & 78,3 & 94,4 \\
& Estimative - reflective & 39,2 & 69,1 & 46,1 & 80,8 \\
& Motivational & 6,4 & 27,9 & 5,4 & 30,3 \\
& Gnostic & 91,4 & 109,8 & 55,2 & 93,3 \\
& Procedural & 78,4 & 122,0 & 83,7 & 115,2 \\
& Estimative-reflective & 43,1 & 75,1 & 51,6 & 74,9 \\
\hline
\end{tabular}

Table 5 shows that the change by criterion $\chi^{2}$ in the experimental group significantly exceeds the change in the control group. The data obtained by calculating indicate significant improvements in the growth of dynamics of the components of professional competence in the experimental group compared with the control group. The value 11,345 corresponds to the beginning area of significance criterion is $\chi^{2}$. Thus, all values that are greater than this value, say about the significance and validity of the results of the basic experiment.

\section{Conclusions}

In General, the analysis of the results of a formative experiment suggest that the level of development of all components of each component of professional competence of students of the experimental group increased significantly compared with students in control groups, with low and average levels decreased significantly. This allows to talk about the positive dynamics of changes in levels: increasing high and sufficient levels and decreasing of the average and low levels, which is proof of the effectiveness in formation the pedagogical experiment conditions.

Based on the data above we can conclude about the effectiveness of the implementation of the model of formation of professional competence of teachers-psychologists, organizational and technological unit, which amounted to pedagogical conditions.

Thus, the proposed model of the formation of professional competence of professionals ensures the formation of professional competence. Such specialist of helping professions will faster and easily adapt to professional psycho-pedagogical activity and perform efficiency and success. 


\section{References}

Aralbaeva, R. K. \& Sheryazdanova, H. T. (2012). Formation of competences in the training of specialists of social sphere in the Republic of Kazakhstan. Scientific notes of Spbgs, 2, 118. St. Petersburg.

Markov, A. K. (1996). Psychology of professionalism (p. 308). Moscow.

Nasledov, A. D., \& Tarasov, S. G. (2001). Use of mathematical methods in Psychology (p59). St. Petersburg.

Platonov, N. M., \& Platonov, M. Y. (2011). Innovations in social work: a manual for students. Moscow: Academy.

Sapargaliyev, A. Zh., Aralbaeva, R. K., Sheryazdanova, H. T., \& Rysbekov, K. K. (2014). Modern problems to updating the content of social education in the Republic of Kazakhstan. Higher education today magazine, 2, 48-51. Moscow.

\section{Copyrights}

Copyright for this article is retained by the author(s), with first publication rights granted to the journal.

This is an open-access article distributed under the terms and conditions of the Creative Commons Attribution license (http://creativecommons.org/licenses/by/3.0/). 